\title{
Personal selling constructs and measures: emic versus etic approaches to cross-national research
}

Personal selling constructs and measures

\author{
Joel Herche
}

Eberhardt School of Business, University of the Pacific, Stockton, California, USA,

\section{Michael J. Swenson}

Marriott School of Management, Brigham Young University, Provo, Utah, USA, and

\section{Willem Verbeke}

\section{School of Economics, Erasmus University, Rotterdam, The Netherlands}

Marketing researchers and practitioners are recognizing that, to succeed, firms must cater to customers within the context of their environment (Wind and Robertson, 1983). This environment is increasingly becoming international. Indeed, customers and competitors are now likely to reside half-way around the world and to possess an entirely different cultural heritage, impacting on personal selling accordingly (Walle, 1986). The complex and demanding global environment certainly affects personal selling - perhaps more so than any other area of the global enterprise. When faced with cross-cultural settings, the necessary attributes for potential success in sales positions can often be disguised, resulting in poor evaluations or exhibitions of cultural idiosyncracies being assessed by an "outsider". This is reflected in Terpstra's (1987, p. 482) comment that "personal selling is more culturebound than impersonal advertising. As a result, even though international business has expanded tremendously in recent decades, personal selling activities are still conducted primarily on a national basis". Thus, a great concern for marketers and sales managers is the development of measures that will be useful in assessing salesperson behaviour and performance across national boundaries.

To what degree can personal selling approaches be generalized across national and cultural boundaries? A more basic question deals with the appropriateness of cross-national application of personal selling constructs and measures that were developed and validated in the USA.

The purpose of our research is to evaluate the transportability of personal selling measures across cultural boundaries. In the next section, we briefly review the concept of measurement development and then distinguish between etic and emic approaches to developing measures for cross-cultural 
European

Journal of Marketing 30,7 applications. Two personal selling constructs are then reviewed - adaptive selling (ADAPTS) and customer-oriented selling (SOCO) - which have been developed in the USA. Next, research expectations about the cross-national dimensionality, reliability and construct validity of ADAPTS and SOCO are developed. Using surveys of US and Dutch salespeople, we apply cross-cultural measurement validation techniques to the measures of adaptive selling (ADAPTS) and customer-oriented selling (SOCO). We conclude with implications for future research.

\section{The emic versus etic dilemma}

The transportation of personal selling constructs and their measures across cultural boundaries is not as simple as it may seem. Indeed, as managers increase their participation in international markets, "the issue of comparability takes on special importance" (Green et al., 1988, p. 48). To the extent that each country is characterized by a distinctive pattern of sociocultural behaviour patterns and values, behavioural phenomena may be expressed in unique ways. Consequently, "relevant constructs will be unique to a given country" (Douglas and Craig, 1983, p. 133). Conversely, demonstrated similarities between countries would facilitate the use of pan-cultural or "culture-free" measures (Elder, 1976). The cross-cultural literature distinguishes between "emic" measures or those that the culture considers meaningful, and the "etic" approach that attempts to make generalizations across cultures or assumes the same global meaningful interpretation (Breslin, 1976; Douglas and Craig, 1983). The use of measures assumed to possess etic characteristics, but which are actually "pseudoetic", is a common violation of basic cross-cultural research paradigms (Sekaran, 1983).

Organizational research that is conducted across cultural boundaries also must consider the culture of the entities being studied. In many cases, this may make the task easier as Sekaran (1983, p. 62) points out: "In organizational research, functional equivalence may not pose serious problems because researchers usually study comparable work settings in different cultures". Researchers of personal selling must deal with the multiple venues of salespeople who labour within their firm's culture and also have professional interaction with customers outside that venue.

When corporate or business cultures are determined to be alike, as might be the case with the personal selling environment in developed economies, adaptation of existing scales is usually appropriate. The influence of competitive activity in a market-based economy could result in an homogenizing effect on its participants with regard to work-related values such as the use of time, motivation to work, accumulation of wealth and achievement. One would therefore expect these value systems to carry somewhat compatible meanings among those working in like occupations in developed economic systems. Because salespeople face several similar "cultural" aspects such as pressure to attain a quota, reporting to a supervisor, or performing a sales presentation, cultural similarity might be considered to be sufficient to warrant 
etic scale adaptation rather than emic scale development (Liander, 1967). Some items, however, still might need to be adapted to the cultural, economic or idiomatic norms of the target culture. Modifications in wording or response formats may be indicated in order to obtain congruence of interpretation of the two cultures involved (Angelmar and Pras, 1978; Douglas and Craig, 1983).

Back-translation, well-known to cross-cultural researchers, is used to transport measures assumed to be etic across linguistic boundaries. It is a process involving translation "from the initial or base language by a bilingual who is a native speaker of the language into which the translation is to be made. This version is then retranslated back into the original language by a bilingual who is a native speaker of the initial language" (Douglas and Craig, 1983, p. 187). The process is discussed in detail by Breslin (1976) and by Sechrest $e$ t al. (1972). Although back-translation is a rigorous exercise, it is of no use for measures that carry emic characteristics because of a lack of cultural relevancy in the target language. Consider, for instance, an item such as: "Proms were an important part of my high school experience". In the USA, proms constitute a significant rite of passage, symbolizing movement into the social and cultural realm of dating, and are often viewed nostalgically by adults. In Europe, these social events have no true parallel, and therefore the translator is faced with the impossible task of searching for a substitute item of functional equivalence. Note that this is not a language translation problem per se, but rather represents a difference in culture.

\section{Measurement theory}

For the purposes of this study, measurement will primarily be concerned with "rules for assigning symbols to objects so as to... represent quantities of attributes numerically" (Nunnaly and Bernstein, 1994, p. 1). This is known as the field of psychometrics or scaling. The goal of measurement development is to produce instruments that carry meaning and are useful for describing and explaining phenomena (p. 5).

Psychometricians consider three criteria in their assessment of the quality of measures. The first is the unidimensionality of the scale. This is concerned with the degree to which the items in the scale load on a single factor (Gerbing and Anderson, 1988). This aspect of a measurement is important, because theory development and testing requires that a single idea be represented by the measure to allow for subsequent testing for correlations with other constructs or differences between groups. Measure fragmentation, or scales that possess multi-dimensional characteristics, represents evidence that the trait allegedly being measured is confounded with other influences. Constructs containing multiple dimensions should be broken down into unidimensional subscales to meet this criterion.

A second aspect of good measures is that they are reliable. This characteristic deals with the stability of the measure over time and the internal consistency of answers on measures containing multiple items (Rust and Cooil, 1994).
Personal selling constructs and measures 
European

Journal

of Marketing

30,7

86
The third indicator of strong measures is validity. This is concerned with the degree to which the measure in fact represents the construct domain. There are several ways in which a measure might not meet this criterion. For example, the items in the measure may represent the named construct (face validity) poorly or the measure may be correlated with theoretically related constructs at a level deemed inadequate by the researcher (convergent validity).

Psychometric approaches to measurement validation only apply to constructs with etic characteristics. Once the meaning of a particular construct of interest is judged to be emic, formal measurement development paradigms become much less structured and comparisons of findings across cultures, as discussed earlier, are not valid. This situation pre-empts any cross-cultural comparisons of sales management constructs if evidence for claiming that the measures being used have etic characteristics (including all of the items in the measure) cannot somehow be obtained. Sales management measures with references to culture-specific phenomena, phrases from folklore or culture-laden proverbs tapping rich, subtle meanings, or the use of stimuli with meanings that may lack cross-cultural "equivalents" signal problems. These characteristics are indicative of emic constructs that should not be used in heterogeneous cultural contexts.

It is only after a measure passes the above screening for emic attributes that traditional psychometric principles can be addressed. The process of measurement validation can be conducted on two levels. The first, and most rigorous, is to undergo independent measurement validation in all the cultures in which the measure will be administered. The time and cost constraints of this approach can be prohibitive. A second approach is to use measures that have been validated in a mono-cultural environment, and to assume etic qualities for the measurement's administration in cultural settings that could be considered somewhat similar. Similarity, in this instance, will most likely refer to levels of industrialization, congruence of expectations of the salesforce roles or other organizational concerns.

Measures that are unidimensional, reliable and valid are said to possess strong psychometric characteristics. The contribution of psychometrics to marketing has been profound and widespread, resulting in the broad acceptance of the basics of psychometrics among sales management researchers (Churchill, 1979). The methodological challenges and costs of data collection have dampened empirical cross-cultural research in personal selling. Notable exceptions to this rule are Moncrief's (1988) work on sales activities of industrial salespeople, Hill and Birdseye's (1989) assessment of selection processes and Hill and Still's (1990) evaluation of salesforce organizations and structures. They concluded that we are at the tip of the international personal selling iceberg, in terms of the potential insights to be obtained from this field of empirical inquiry. If this potential is to be realized, the emic/etic aspects of cross-cultural research in personal selling must be evaluated. 


\section{Personal selling constructs}

Two useful constructs - adaptive selling (Weitz, 1981) and customer-oriented selling (Saxe and Weitz, 1982) - have provided novel insights into the meaning and causes of salesperson performance and have served as the basis for much research (Michaels and Day, 1985; Saxe and Weitz, 1982; Spiro and Weitz, 1990; Weitz, 1981). The practice of adaptive selling has been defined as "the altering of sales behaviours during a customer interaction or across customer interactions based on perceived information about the nature of the selling situation" (Weitz et al., 1986, p. 175). Salespeople practise adaptive selling when they use a unique approach for each customer and when they make adjustments during each interaction (Spiro and Weitz, 1990). Spiro and Weitz (1990) developed the ADAPTS scale to measure the extent to which salespeople practise adaptive selling.

Customer-oriented selling is "the degree to which salespeople practise the marketing concept by trying to help their customers make purchase decisions that will satisfy customer needs" (Saxe and Weitz, 1982, p. 344). While the notion of customer-oriented selling is not necessarily new (Strong, 1925), until recently, little empirical research had examined its effectiveness. Saxe and Weitz (1982) developed the SOCO (selling orientation-customer orientation) scale to measure the extent to which salespeople practise customer-oriented selling.

Spiro and Weitz (1990) call for additional research to investigate the validity of the ADAPTS scale further. Similarly, Saxe and Weitz (1982) solicit research to validate the SOCO scale further. While researchers have validated these scales in a number of settings in the USA (Brown et al., 1991; Michaels and Day, 1985; Swenson and Herche, 1994), there has been no effort to validate the measures cross-culturally. Thus, translating the scales into other languages and testing them in other countries is a needed next step. The research presented here is intended to address this issue.

\section{Research questions}

There should be a substantial overlap in the cultural aspects of selling environments in developed economies, although the cultural backgrounds of various national samples might be viewed as quite different. For example, the need to satisfy customers and supervisors, meet quotas, and perform sales presentations would be common to all milieus. It might therefore be expected that measures developed in one setting should also be appropriate for the other, provided that they have undergone a rigorous back-translation exercise. In other words, personal selling constructs, in general, should exhibit etic characteristics within developed, market-oriented economies. If the constructs and measures are international in scope, SOCO and ADAPTS should be psychometrically sound across countries.

\section{Dimensionality}

A scale that is applicable to The Netherlands as well as the USA, should exhibit a consistent factor pattern across the two countries. This leads us to our first set
Personal selling

constructs and measures 
European

Journal

of Marketing

30,7

88

of research questions. Is the factor structure for ADAPTS consistent across the two countries? Is the factor structure for SOCO consistent across the two countries?

\section{Internal consistency}

The internal consistency of several types of measures has been found to vary widely across cultural settings (Davis et al., 1981). For a scale to be deemed appropriate across countries, internal consistency should be high and equal. This leads to our second set of research questions. Are the internal consistency estimates for the measures high and equal across the two countries?

\section{Validity}

Our final set of research questions addresses the degree to which the measures represent the construct of interest. To evaluate the discriminant validity of ADAPTS and SOCO, measures assessing each sample's attitude towards ethical misconduct (Hunt et al., 1984) and realism of the sales job (Dubinsky et al., 1986) were included in the questionnaire. Because the ethical scale and the realism scale measure characteristics different from ADAPTS and SOCO, the properties of the scaling procedures should differ, Trandis and Marin (1983). Thus, are ADAPTS and SOCO distinct from the ethical measure and the realism measure? That is, are the measures unique and not simply a reflection of other variables (Trandis and Marin, 1983)?

\section{Method}

The samples

Three independent surveys of salespeople were conducted to test the above research questions. The measurement instrument was initially developed and administered in the USA. It was pre-tested on a single-firm pilot study of 45 salespeople. The questionnaire was designed to measure adaptability and customer orientation, in addition to soliciting responses on a number of demographic variables. After minor changes were incorporated for readability and conciseness, a final document was mailed to 1,800 sales representatives in the USA who were randomly selected from a commercial list broker's master list. The data were collected from salespeople using self-administered questionnaires. The mailing was followed by a reminder message. Assurances were made that all responses would be confidential.

In all, 271 usable responses were received for a response rate of 15 per cent. The high rate of non-response is not uncommon when marketing practitioners in the USA, and more specifically salespeople, are used as the sample, when the study has no sponsorship other than university affiliation, and when inducements are not provided (Achrol and Stern, 1988; Gatignon and Robertson, 1989; Sujan and Weitz, 1986). An attempt was made to estimate the non-response bias by comparing the distributions of demographic variables for the first two-thirds of respondents with those of the last third, as suggested by Armstrong and Overton (1977). No significant differences were observed. 
A second survey in the USA involved obtaining co-operation from three high technology firms with large salesforces. A letter was sent out to an arbitrarilyselected subset of salespeople who were asked by their sales vice president to participate in the study. This survey also employed the questionnaire described above, and 129 responses ( 45 per cent response rate) were obtained in this fashion.

The incomes and genders of the respondents in each sample were compared; the chi-squared statistics were not statistically significant. The industry characteristics of the supervisor-endorsed sample limited the validity of comparison of some demographic characteristics such as age and education. Because the differences in these variables were expected, the two groups were combined into a single US sample consisting of 400 responses.

Salespeople in The Netherlands were selected to represent European sales personnel. While one would like to get a more geographically and nationally diverse sample, financial and other constraints prevented this approach. This limitation notwithstanding, The Netherlands offers an appropriate contrast to the USA with regard to cultural, economic and political characteristics and the evaluation of the research questions. Back-translation was used to transport the measures across linguistic boundaries following the process suggested by Douglas and Craig (1983). The sample consisted of salespeople representing a cross-section of sales organizations. Of the 116 companies contacted, 100 companies agreed to participate in the study. Sales managers delivered the questionnaires to their salespeople. In all, 819 questionnaires were delivered and 245 responses were obtained for a return rate of 30 per cent.

The characteristics of the sample, with regard to their industrial classification and national origin, are presented in Table I. The proportional representation of the industries is not consistent across the national samples (chi square $=39.7, p<0.000$ ). The stronger representation of services and high technology in the USA could signal problems in comparisons of the samples stemming from industry-specific responses. This issue will be addressed following the measurement validation.

\section{Measurement validations}

The emic/etic measurement concerns, summarized above, lead to a confirmatory assessment of the functional and metric equivalence of the measures through subjective and quantitative means. A panel of Dutch graduate business students was employed for expert judging to determine if the constructs in question, customer orientation and adaptability of selling style, would be considered similarly in The Netherlands and in the USA. A high degree of similarity was reported among the panelists.

Metric equivalence was assessed via statistical analyses of dimensionality, reliability and discriminant validity.
Personal selling constructs and measures 
European

Journal of Marketing 30,7

\section{0}

Dimensionality and internal consistency

Consistency of factor patterns, factor loadings and error variances was conducted in a manner similar to that suggested by Kumar $e t$ al. (1995). The initial step in this process involved determining the factor patterns in one culture and comparing the loading patterns with those of the second culture.

\begin{tabular}{lrcrc}
\hline Industry & USA & The Netherlands & \multicolumn{2}{c}{ Total } \\
& & & No. & $\%$ \\
\hline High technology & 143 & 49 & 192 & 31.6 \\
Manufacturing & 173 & 168 & 341 & 56.1 \\
Services & 59 & 16 & 75 & 12.3 \\
\hline
\end{tabular}

Since both ADAPTS and SOCO were developed in the USA, it was used as a base culture to determine factor structure. The second step involved constraining the Dutch data to fit the American factor loading pattern to identify items that were not transferable. These items were then deleted and confirmatory analyses redone. The final factor patterns and loadings are summarized in Table II.

The ADAPTS measure was found to possess strong evidence of comparability of dimensionality across the two cultures tested. After deleting item 16 due to lack of convergence, a single-factor solution was suggested in the USA sample (eigenvalue of 10.1 with 63.2 per cent of variation explained). This structure was then subjected to confirmatory factor analysis using EQS. The confirmatory analyses showed strong evidence of the unidimensionality of the measure in the USA (chi-square fit of 413 with 90 degrees of freedom, comparative fit of $0.93, p<0.000$ ). The exploratory analysis revealed a similar structure in The Netherlands (eigenvalue of 8.3 with 52.5 per cent explained variance) with similar findings from the confirmatory approach (chi-square fit of 270 with 90 degrees of freedom, comparative fit of $0.91, p<0.001$ ).

SOCO was found to possess a more fragmented factor structure in both countries. Exploratory analyses and the resulting assessment of the scree plots on the US sample suggested that the measure could be summarized using two underlying factors (henceforth SOCOA and SOCOB) that explained 50 per cent of the variance. The observed factor structure appeared to reveal a positive/negative wording polarity for the SOCO scale. It has been suggested that attribution bias, resulting from statement polarity, can fragment measure dimensionality (Herche and Engelland, 1996). EQS was then used to assess the fit of the solutions in the US sample. The fit statistics for the revised two-factor SOCO measurement model revealed strong characteristics: chi-square $=413 ; 90$ degrees of freedom; comparative fit of $093 ; p<0.001$. The Dutch sample was evaluated in the same way. The exploratory analyses showed a much higher degree of fragmentation, as the first two factors explained only 25 per cent of 


\begin{tabular}{|c|c|c|c|}
\hline Scale & USA & The Netherlands & $\begin{array}{l}\text { Personal selling } \\
\text { constructs and }\end{array}$ \\
\hline \multicolumn{3}{|l|}{ SOCOA } & measures \\
\hline SOCO1 & 0.74 & 0.48 & \\
\hline SOCO6 & 0.66 & 0.30 & \\
\hline SOCO7 & 0.88 & 0.26 & \\
\hline $\mathrm{SOCO9}$ & 0.59 & 0.31 & 91 \\
\hline SOCO12 & 0.75 & 0.29 & \\
\hline SOCO15 & 0.68 & 0.29 & \\
\hline SOCO16 & 0.72 & 0.59 & \\
\hline SOCO19 & 0.76 & 0.46 & \\
\hline $\mathrm{SOCO} 21$ & 0.55 & 0.26 & \\
\hline SOCO22 & 0.43 & 0.31 & \\
\hline SOCO23 & 0.55 & 0.21 & \\
\hline \multicolumn{4}{|l|}{$S O C O B$} \\
\hline SOCO3 & 0.58 & 0.44 & \\
\hline SOCO5 & 0.58 & 0.65 & \\
\hline SOCO8 & 0.64 & 0.63 & \\
\hline SOCO10 & 0.61 & 0.45 & \\
\hline SOCO11 & 0.62 & 0.28 & \\
\hline SOCO13 & 0.73 & 0.58 & \\
\hline SOCO14 & 0.73 & 0.49 & \\
\hline $\mathrm{SOCO18}$ & 0.67 & 0.24 & \\
\hline SOCO20 & 0.61 & 0.37 & \\
\hline $\mathrm{SOCO} 24$ & 0.73 & 0.20 & \\
\hline \multicolumn{4}{|l|}{ ADAPTS } \\
\hline ADAPTS1 & 0.85 & 0.60 & \\
\hline ADAPTS2 & 0.91 & 0.85 & \\
\hline ADAPTS3 & 0.82 & 0.68 & \\
\hline ADAPTS4 & 0.92 & 0.72 & \\
\hline ADAPTS5 & 0.72 & 0.59 & \\
\hline ADAPTS6 & 0.71 & 0.64 & \\
\hline ADAPTS7 & 0.86 & 0.83 & \\
\hline ADAPTS8 & 0.73 & 0.63 & \\
\hline ADAPTS9 & 0.80 & 0.65 & \\
\hline ADAPTS10 & 0.67 & 0.65 & \\
\hline ADAPTS11 & 0.69 & 0.74 & \\
\hline ADAPTS12 & 0.78 & 0.76 & Table II. \\
\hline ADAPTS13 & 0.76 & 0.80 & Comparative factor \\
\hline ADAPTS14 & 0.63 & 0.67 & loadings CFA \\
\hline ADAPTS15 & 0.83 & 0.60 & assessment \\
\hline
\end{tabular}

the variation. The results of the fit assessment on the Dutch data were stronger: chi-square $=270 ; 90$ degrees of freedom; comparative fit of $0.91 ; p<0.001$.

Although the revised SOCO measurement model showed only a moderate degradation in fit as it was applied to the Dutch data, the inconsistency of the pattern of factor loadings (see Table II) revealed in the confirmatory assessment were the source of some concern regarding SOCO's etic characteristics. 
European Journal of Marketing 30,7

92

The tests for this problem were conducted using Cronbach's alpha, average inter-item correlations and item-total correlations. As shown in Table III, alpha coefficients ranged widely for the two SOCO subscales depending on the national sample, while ADAPT obtained an "exemplary" rating in both countries when compared to Robinson et al.'s (1991) benchmark criterion of 0.8 . SOCOA and SOCOB both fell below the often-cited acceptable minimum of 0.7 (Rust and Cooil, 1994) when transported to the Dutch sales personnel, although some psychometricians claim that an alpha coefficient as low as 0.6 does not represent a problem (Kumar et al., 1995). The item-total correlations were generally strong across both samples. Most average inter-item correlations would be seen as very strong except for SOCOA in The Netherlands which fell in the upper range of "moderate" using the Robinson et al (1991) guidelines.

Table III. Internal consistency assessments

\begin{tabular}{lccc}
\hline & SOCOA & SOCOB & ADAPTS \\
\hline Coefficient $\alpha$ & & & \\
USA & 0.89 & 0.88 & 0.96 \\
The Netherlands & 0.56 & 0.67 & 0.93 \\
Inter-item correlations & & & \\
USA & 0.23 & 0.38 & 0.30 \\
The Netherlands & 0.18 & 0.25 & 0.27 \\
Item-total correlations & & & \\
USA & 0.55 & 0.67 & 0.59 \\
The Netherlands & 0.52 & 0.57 & 0.56
\end{tabular}

Industry-specific effects, discussed earlier, could be expected to impact the psychometric properties of measures. That is, items might be interpreted differently in contrasting industrial settings where the meaning of a customer orientation could carry idiosyncratic implications. To test for this, the industrial classifications provided by the respondents were grouped into the three categories reported in Table I. None of the mean values of the variables of interest (SOCOA, SOCOB or ADAPTS) revealed statistically significant differences between industries, suggesting that industry effects need not be a source of concern in subsequent analyses.

\section{Construct validity}

Validity assessments are especially difficult in cross-cultural settings because alternative methods to measure constructs of interest usually have not been developed. Convergent validity, in particular, often cannot be assessed because multi-trait multi-method approaches are dependent on such measures. Such was the case in this study.

An assessment of the discriminant validity of the measures is reported in Table IV. Two three-item measures were chosen for the analysis: realism of job expectations (REAL), developed by Dubinsky et al. (1986), and tolerance of 
ethical misconduct by the salesperson's firm (ETH), created by Hunt $e$ t al. (1984). Although it is possible that these measures do not possess the same meanings in the Dutch culture as they do in the USA, it was deemed improbable that they were viewed as similar to the two SOCO dimensions or ADAPTS, and were therefore seen as appropriate candidates for inclusion. These measures were correlated with the summated scores for each construct to assess discriminant validity.
Personal selling constructs and measures

\begin{tabular}{|c|c|c|c|c|c|c|c|}
\hline & $\begin{array}{r}\text { SO } \\
\text { USA }\end{array}$ & $\begin{array}{l}\text { COA } \\
\text { The } \\
\text { Netherlands }\end{array}$ & $\begin{array}{r}\text { SOC } \\
\text { USA }\end{array}$ & $\begin{array}{l}\text { OB } \\
\text { The } \\
\text { Netherlands }\end{array}$ & $\begin{array}{r}\mathrm{AD} \\
\mathrm{USA}\end{array}$ & $\begin{array}{l}\text { APTS } \\
\text { The } \\
\text { Netherlands }\end{array}$ & \\
\hline $\begin{array}{l}\text { Correlation with } \\
\text { REAL }\left(\alpha_{\text {USA }}=0.80\right) \\
\qquad\left(\alpha_{\text {NET }}=0.79\right)\end{array}$ & $0.13^{\mathrm{a}}$ & 0.00 & 0.05 & 0.04 & $0.17^{a}$ & 0.09 & \\
\hline $\begin{array}{l}\text { Correlation with } \\
\text { ETH }\left(\alpha_{\mathrm{USA}}=0.79\right) \\
\qquad\left(\alpha_{\mathrm{NET}}=0.71\right) \\
\text { Note: } \\
{ }^{\text {aCorrelations statistic }}\end{array}$ & $\begin{array}{l}0.20^{\mathrm{a}} \\
\text { signific }\end{array}$ & $\begin{array}{c}0.05 \\
\text { ant at } \alpha=0.05\end{array}$ & $0.15^{\mathrm{a}}$ & 0.09 & 0.05 & 0.07 & $\begin{array}{r}\text { Table IV. } \\
\text { Discriminant validity } \\
\text { assessments }\end{array}$ \\
\hline
\end{tabular}

As shown in Table IV, REAL and ETH were found to possess Strong evidence of internal consistency across both national samples, thus increasing the power of subsequent correlational analyses. Four of the six correlation coefficients for the USA sample were statistically significant. It should be noted, however, that even the highest of the 12 correlation coefficients $(0.20$ for ETH and SOCOA in the US sample) represents roughly 4 per cent of variation in common, highlighting the rigorous standards of the tests. There was no evidence of discriminant validity problems in the Dutch sample.

Although one can always seek further evidence of validation, the consistency of the psychometric properties of ADAPTS was seen as sufficient to warrant direct comparison of the scores between the two samples. SOCO, owing to its dimensional fragmentation in both samples resulting in difficulties in interpretation as well as the degradation of internal consistency of the two subscales in The Netherlands, could be characterized as needing further refinement for both domestic and cross-cultural applications.

\section{Discussion}

The development of multi-item scales to assess latent attitudinal and behavioural constructs was an emphasis of marketing research even before the introduction of Churchill's (1979) paradigm of measurement development. Cross-cultural validation of measures, however, has not been pursued with the same enthusiasm, probably because of the cost and difficulty of obtaining international data (Albaum and Peterson, 1984). As the growth of economic 
European

Journal of Marketing 30,7

\section{4}

integration schemes and global organizations mandates the management of salesforces across cultural and national boundaries, the need to understand the applicability of theories and measures developed in monolithic cultural environments gains salience. Indeed, measures with sound psychometric properties across countries will facilitate sales management strategies in foreign countries. Yet, organizational and management science has made little progress in addressing the global context of management (Boyacigiller and Alder, 1991; Hofstede, 1993). The current study represents an effort to apply cross-cultural measurement validation techniques to two well-known personal selling scales.

We examine the measures of adaptive selling (ADAPTS) and customeroriented selling (SOCO) in cross-national context. Strong support for the ADAPT's factor structure, internal consistency, and discriminant validity is found across the two countries. The results pertaining to SOCO's psychographic properties are less favourable. Because of its dimensional fragmentation in both samples and its degradation of internal consistency of the two subscales in The Netherlands, SOCO may need further refinement.

Our findings suggest several implications for sales researchers. It has been argued that all cross-cultural research should adopt a combination of emic and etic approaches (Berry, 1969). Moreover, contemporary theories agree that neither the etic nor the emic perspectives are optimal when used in isolation (Segall et al., 1990). Blindly transporting instruments from one culture to another may produce measures that are less useful in describing and explaining phenomena in the community of interest. The weak transferability of the SOCO scale highlights the need to evaluate measures beyond a standard backtranslation exercise. If cultures are determined to be alike, however, then instruments or scales may be transported across national boundaries to measure constructs that relate to the common culture. That is, the pure etic approach used in this study may be applicable to other selected measures of personal selling, because salespeople share a common "culture" to the degree that organizational environments and professional goals are similar across national venues. If this is true, it could facilitate cross-cultural comparisons of salesforce characteristics and aid in the development of theories explaining the relationships between culture and sales management technology by allowing cross-cultural researchers to employ the less rigorous etic approach to adapt measures to various cultural/linguistic settings.

Judicious application of etic approaches to cross-cultural salesforce research will allow for the generation of a literature base dealing with theory development and validation of cultural impacts on personal selling, sales management and the sales profession in general. Up to this point, most crosscultural research in personal selling has dealt with comparisons of certain constructs in diverse environments. Although this comparative approach is helpful, a development of theory on how certain aspects of culture impact on various sales activities would be more generalizable and, therefore, of greater 
use to readers. Such research activities can also serve to replicate the theories originally developed and validated in a mono-cultural environment.

The task of creating and employing sound measurement instruments for personal selling constructs across national and cultural boundaries remains a situation-specific exercise. Recognition of cultural variables can contribute greatly to our understanding of personal selling approaches in the global context. Therefore, while many business and professional cultures have similarities, those transporting personal selling constructs across cultural boundaries should be appraised of the problems highlighted here.

Several aspects of the external validity of the findings need to be addressed. First, measures dependent on or tied to national culture rather than business or corporate culture could be expected to be more susceptible to culture-related distortions in measurement. The findings for SOCO and ADAPTS may not be representative of those of many scales dealing more with personal rather than professional activities. Misunderstandings may be increased when scale items seek responses from outside the shared domain of selling activities.

Second, the scales selected for this research are not necessarily representative of all personal selling scales. ADAPTS and SOCO were selected because of their reputation, familiarity, and convenience (i.e. public domain). Consequently, generalizations beyond the scales used in this study are not warranted. Future research directed at assessing the transportability of other personal selling scales would be potentially highly rewarding.

Finally, the two-nation sample employed in this study should be viewed as an exploratory effort in this field. Further research incorporating additional national samples could provide a basis for extending the generalizability of the findings. If personal selling measures can be convincingly shown to be transportable across cultural/national settings, support would be provided for adopting an etic approach to personal selling strategies, policies and theories.

\section{References}

Achrol, R.S. and Stern, L.W. (1988), "Environmental determinants of decision-making uncertainty in marketing channels", Journal of Marketing Research, Vol. 25, February, pp. 36-50.

Albaum, G. and Peterson, R.A. (1984), "Empirical research in international marketing. 1976-1982", Journal of International Business Studies, Vol. 15, Spring/Summer, pp. 161-73.

Angelmar, R. and Pras, B. (1978), "Verbal rating scales for multi-national research", European Research, Vol. 6, March, pp. 62-7.

Armstrong, J.S. and Overton, T.S. (1977), "Estimating nonresponse bias in mail surveys", Journal of Marketing Research, Vol. 14, August, pp. 396-402.

Berry, J.W. (1969), "On cross-cultural comparability”, International Journal of Psychology, Vol. 4, pp. 119-238.

Boyacigiller, N. and Alder, N.J. (1991), "The parochial dinosaur: organizational science in a global context", Academy of Management Review, Vol. 16, 1991, pp. 262-90.

Breslin, R.W. (1976), Translation: Applications and Research, Wiley, New York, NY, 1976.

Brown, G., Wilding, R.E. II and Coulter, R.L. (1991), "Customer evaluation of retail salespeople utilizing the SOCO scale: a replication, extension, and application", Journal of the Academy of Marketing Science, Vol. 19, Fall, pp. 347-51.

Personal selling constructs and measures

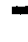




\section{European Journal of Marketing 30,7}

Churchill, G.A.Jr (1979), "A paradigm for developing better measures of marketing constructs", Journal of Marketing Research, Vol. 16, February, pp. 64-73.

Davis, H.L., Douglas, S.P. and Silk, A.J. (1981), "Measure unreliability: a hidden threat to crossnational marketing research?", Journal of Marketing, Vol. 45, Spring, pp. 98-109.

Douglas, S.P. and Craig, C.S. (1983), International Marketing Research, Prentice-Hall, Englewood Cliffs, NJ.

Dubinsky, A.J., Howell, R.D., Ingram, T.N. and Bellenger, D.N. (1986), "Salesforce socialization”, Journal of Marketing, Vol. 50, October, pp. 192-207.

Elder, J.W. (1976), "Comparative cross-national methodology", Annual Review of Sociology, Annual Reviews, Palo Alto, CA.

Gatignon, H. and Robertson, T.S. (1989), "Technology diffusion: an empirical test of competitive effects", Journal of Marketing, Vol. 53, January, pp. 35-49.

Gerbing, D.W. and Anderson, J.C. (1988), "An updated paradigm for scale development incorporating unidimensionality and its assessment", Journal of Marketing Research, Vol. 25, May, pp. 186-92.

Green, P.E., Tull, D.S. and Albaum, G. (1988), Research for Marketing Decisions, Prentice-Hall, Englewood Cliffs, NJ.

Herche, J. and Engelland, B. (1996), "Reversed-polarity items and scale unidimensionality", Journal of the Academy of Marketing Science, Vol. 24, Fall (in press).

Hill, J.S. and Birdseye, M. (1989), "Salesperson selection in multinational corporations: an empirical study", Journal of Personal Selling and Sales Management, Vol. 9, Summer, pp. 39. 47.

Hill, J.S. and Still, R.R. (1990), “Organizing the overseas sales force: how multinationals do it”, Journal of Personal Selling and Sales Management, Vol. 10, Spring, pp. 57-66.

Hofstede, G. (1993), "Cultural constraints in management theories", Academy of Management Executive, Vol. 7, pp. 81-94.

Hunt, S.D., Chonko, L.B. and Wilcox, J.B. (1984), "Ethical problems of marketing researchers", Journal of Marketing Research, Vol. 21, August, pp. 309-24.

Kumar, N., Scheer, L. and Steenkamp, J.B. (1995), "The effects of supplier fairness on vulnerable resellers", Journal of Marketing Research, Vol. 32, February.

Liander, B. (1967), Comparative Analysis for International Marketing, Marketing Science Institute, Boston, MA.

Michaels, R.E. and Day, R.L. (1985), "Measuring customer orientation of salespeople: a replication with industrial buyers", Journal of Marketing Research, Vol. 22, November, pp. 443-6.

Moncrief, W.C. (1988), "A comparison of sales activities in an international setting", Journal of International Consumer Marketing, Vol. 1, pp. 45-62.

Nunnaly, J.C. and Bernstein, I.H. (1994), Psychometric Theory, McGraw-Hill, New York, NY.

Robinson, J.P., Shaver, P.R. and Wrightsman, L.S. (1991), "Criteria for scale selection and evaluation", in Robinson, J.P., Shaver, P.R. and Wrightsman, L.S. (Eds), Measures of Personality and Social Psychological Attitudes, The Academic Press, San Diego, CA, pp. 1-13.

Rust, R.T. and Cooil, B. (1994), "Reliability measures for qualitative data: theory and implications", Journal of Marketing Research, Vol. 31, February, pp. 1-15.

Saxe, R. and Weitz, B.A. (1982), "The SOCO scale: a measure of the customer orientation of salespeople", Journal of Marketing Research, Vol. 19, August, pp. 343-51.

Sechrest, L., Fay, T.L. and Hafeez Zaidi, S.M. (1972), "Problems of translation in cross-cultural research",Journal of Cross-cultural Psychology, Vol. 3, March, pp. 41-56.

Segall, M.H., Dasen, P.R., Berry, J.W. and Poortinga, Y.H. (1990), Human Behavior in Global Perspective: An Introduction to Cross-cultural Psychology, Pergamon, New York, NY. 
Sekaran, U. (1983), "Methodological and theoretical issues and advancements in cross-cultural research", Journal of International Business Studies, Vol. 14, Fall, pp. 61-73.

Spiro, R.L. and Weitz, B.A. (1990), "Adaptive selling: conceptualization, measurement and nomological validity", Journal of Marketing Research, Vol. 28, February, pp. 61-9.

Strong, E.K. Jr (1925), "Theories of selling”, Journal of Applied Psychology, Vol. 9, January, pp. 75 86.

Sujan, H. and Weitz, B. (1986), "The effects of level and type of effort on salesperson performance", working paper, Pennsylvania State University, University Park, PA.

Swenson, M.J. and Herche, J. (1994), "Social values and salesperson performance: an empirical examination", Journal of the Academy of Marketing Science, Vol. 22, Summer.

Terpstra, V. (1987), International Marketing, Holt, Rinehart \& Winston, New York, NY.

Trandis, H.C. and Marin, G. (1983), "Etic plus emic versus pseudoetic: a test of a basic assumption of contemporary cross-cultural psychology", Journal of Cross-cultural Psychology, Vol. 14, December, pp. 489-500.

Walle, A.H. (1986), "Conceptualizing personal selling for international business: a continuum of exchange perspective", Journal of Personal Selling and Sales Management, Vol. 6, November, pp. 9.17.

Weitz, B.A. (1981), "Effectiveness in sales interactions: a contingency framework", Journal of Marketing, Vol. 45, Winter, pp. 85-103.

Weitz, B.A., Sujan, H. and Sujan, M. (1986), "Knowledge, motivation, and adaptive behavior: a framework for improving selling effectiveness", Journal of Marketing, Vol. 50, October, pp. 174-91.

Wind, Y. and Robertson, T.S. (1983), "Marketing strategy: new directions for theory and research", Journal of Marketing, Vol. 47, Spring, pp. 12-21.
Personal selling constructs and measures 
Copyright of European Journal of Marketing is the property of Emerald. The copyright in an individual article may be maintained by the author in certain cases. Content may not be copied or emailed to multiple sites or posted to a listserv without the copyright holder's express written permission. However, users may print, download, or email articles for individual use. 